\title{
Total Phenolic Content and Antioxidant Activity of Leaves and Drupes in Major Greek Olive Varieties
}

\section{Georgios MITSOPOULOS ${ }^{1}$, Vassiliki PAPAGEORGIOU², Michael KOMAITIS ${ }^{2}$, Marianna HAGIDIMITRIOU ${ }^{1 *}$}

\author{
${ }^{1}$ Agricultural University of Athens, Department of Crop Science, Pomology Laboratory, Iera Odos 75, 11855, Athen, \\ Greece;mit1972gogo@yahoo.gr;marianna@aun..gr(*orrespondingauthor) \\ ${ }^{2}$ Agricultural University of Athens, Department of Food Science and Human Nutrition, Food Chemistry and Analysis Laboratory, Iera Odos 75, 11855, Athens, \\ Greece;m.komaitis@auagr;vapg13@hotmail.com
}

\begin{abstract}
The total phenolic content and the antioxidant activity were determined for leaves and drupes of the major Greek olive varieties 'Koroneiki', 'Lianolia Kerkyras', 'Mastoidis', 'Adramytini', 'Megaritiki', 'Gaidourelia', 'Kalamata', 'Konservolia', 'Chalkidiki' and the Spanish variety 'Arbequina'. Leaves were collected in April, September and December, and drupes were collected green and black, for two consecutive years and investigated for their total phenolic content and antioxidant activity, using the Folin-Ciocalteu and the DPPH assays, respectively. The data obtained from this work showed that the total phenolic content and the antioxidant activity of all varieties per tissue have varied significantly since different varieties exhibited statistically significant different values. Furthermore, within each variety, tissue was an important parameter for both the total phenolic content and the antioxidant activity, as different tissues exhibited statistically significant differences for both measurements. For the varieties studied, and for both years, new season leaves on April showed the highest total phenolic content followed by green and black drupes with a few exceptions. Also new season leaves on April showed the highest total phenolic content than the leaves of September and December of the same year with a few exceptions also. A positive correlation $\left(\mathrm{r}=0.793^{* *}\right)$ between the antioxidant activity and the total phenolic content was found.
\end{abstract}

Keywords: DPPH, drupes, Folin-Ciocalteu, leaves, olive, Olea europaea ssp. sativa

\section{Introduction}

For many centuries the history of olive tree and its products is inextricably tied to the history of Greece. The olive products, olive oil and table olives, play an important socioeconomic role in the country and an integral part to the Mediterranean diet, a diet with high content of bioactive substances such as vitamins, flavonoids and polyphenols.

Regarding polyphenols, literature presents a vast amount of work on the protective effects of phenolic compounds as antioxidants. Moreover, their positive effect against cardiovascular diseases and certain cancers has also been well demonstrated (Andrikopoulos et al., 2002; Kris-Etherton et al., 2002; Hertog et al., 1995). Additionally, many reports in the literature demonstrate the positive effect of olive oil and olive drupes in human health. Antioxidant (Ghisalberti, 1998; Le Tutour and Guedon, 1992; Owen et al., 2000), antimicrobial (Ghisalberti, 1998; Walter et al., 1973), antihypertensive (Ghisalberti, 1998; Visioli and Galli, 1994, 1998; Ziyyat et al., 1997), vasodilator (Zarzuelo et al., 1991) and hypoglycaemic
(Gonzalez et al., 1992) effects of the olive leaf extract or individual components have mentioned.

The role of phenolic compounds in higher plants is mostly focused in the response of plants to environmental stresses, both abiotic and biotic. Phenolic compounds play an important structural role, as lignin is the dominant phenolic component of the cell wall (Whetten and Sederoff, 1995). They also play an important functional role, since cinamic and p-coumaric acid act as growth regulators (Harborne, 1993). Additionally, their defensive role is well known, since the presence of flavonoids in the cell walls of the epidermal cells allow the protection of these cells from ultraviolet (UV) radiation. Oleuropein and its derivatives have repellent properties as they prevent the olive fly to deposit eggs on the drupes. Other phenolic substances such as caffeic acid, tyrosol, hydroxytyrosol, and chlorogenic acid, have antibacterial properties (Soler-Rivas et al., 2000; Vermerris and Nicholson, 2006). Another group of flavonoids, the anthocyanins, play an important role in reproduction since they are responsible for the colours of the petals, attracting the insects that carry pollen (Markham et al., 2000). 
156

Finally, phenolic compounds play an important role in the organoleptic characteristics of plant products. In olive, the characteristic bitter taste and the colour of ripe fruits is due to oleuropein and its derivatives (Ryan and Robards, 1998). In unripe green olives, the amount of oleuropein is high and the fruit is very bitter. As ripeness progresses, the content of oleuropein in the drupes reduces and the colour slowly turns black.

In the present study the total phenolic content, as well as, the antioxidant activity were studied for different olive tissues (leaves and drupes) of ten olive varieties, during various developmental stages within the period of two consecutive years.

One of the main aims of this study was to compare major Greek olive varieties in regard to their phenolic content and total antioxidant activity, since limited reports are present in international literature on the matter.

Colorimetric Folin-Ciocalteu assay (Singleton and Rossi, 1965) was used for the estimation of the total phenolic content. This assay has the advantages of been reproducible, its basis is understood, and its applicability has been verified. On the other hand, differences in reactivity between different phenols make it difficult to compare samples with significantly different phenolic composition (Singleton et al. 1999). The 2,2-diphenyl-1picryhydrazyl free radical (DPPH) scavenging assay was used for the determination of total antioxidant activity.

\section{Materials and Methods}

\section{Plantmaterial}

Samples of leaves and drupes of the olive varieties 'Koroneiki', 'Lianolia Kerkyras', 'Mastoidis', 'Arbequina', 'Adramytini', 'Megaritiki', 'Gaidourelia', 'Kalamata', 'Konservolia' and 'Chalkidiki', were collected at different seasons during two consecutive years. New season leaves were collected in April, green drupes in October and black drupes in December for both years. Mature leaves were collected in October and December of the second year. The samples were collected from six years old olive trees kept in pots at the Agricultural University of Athens orchard. Following their collection, all plant material was put in plastic bags, by means of a cooler transported to the laboratory and stored at $-80^{\circ} \mathrm{C}$ until analysis.

\section{Reagents}

Folin-Ciocalteu reagent was obtained from Merck (Darmstadt, Germany). The remaining reagents were all purchased from Sigma-Aldrich (Steinheim, Germany). Distilled water was used throughout.

Extraction of soluble (free and conjugated) phenolic compounds

The extraction procedure was performed according to Ryan et al. (2002), with slight modifications. At room temperature, $4 \mathrm{~mL}$ of methanol were added to $0.8 \mathrm{~g}$ of plant tissue (leaves or drupes) and homogenized with an Ultra-Turrax T25 Basic homogenizer. The solution was left in the dark for 30 minutes and then centrifuged for 6 minutes at $4000 \mathrm{rev} / \mathrm{min}$ in a Labofuge 400 centrifuge. The supernatant was collected and placed in the dark. In the precipitate recovered, $4 \mathrm{~mL}$ of methanol were further added and the above procedure was repeated once more. The supernatants were combined and filtered through a Buchner apparatus. In order for the lipids and pigments to be removed, the filtered samples were treated three times with $5 \mathrm{~mL}$ of hexane. The hexane layer was removed and the resulting extract was stored at $-20^{\circ} \mathrm{C}$ until it was analyzed.

\section{Determination of total phenolic content}

Total phenolic content was determined according to the Folin-Ciocalteu colorimetric method (Singleton and Rossi, 1965) and gallic acid as a standard. The method is based on the colour reaction of the Folin-Ciocalteu reagent with the hydroxyl groups. In $0.5 \mathrm{~mL}$ of the diluted extract $(1: 10 \mathrm{v} / \mathrm{v}), 5 \mathrm{~mL}$ of diluted Folin-Ciocalteu reagent $(1: 10 \mathrm{v} / \mathrm{v})$ was added. The mixture was stirred and allowed to stand for 3 minutes. Then, 4 $\mathrm{mL}$ of aqueous $\mathrm{Na}_{2} \mathrm{CO}_{3}$ solution $(1 \mathrm{M})$ was added. The solution was stirred gently and incubated in a water bath at $45^{\circ} \mathrm{C}$ for 15 minutes. Absorbance was measured at $765 \mathrm{~nm}$ using a Jasco V530 UV/VIS spectrophotometer and quantitated using a gallic acid calibration curve. The total phenolic content was expressed as mg of gallic acid equivalents (GAE) per gram of fresh tissue.

\section{Determination of antioxidant activity}

The antioxidant activity was estimated by the 2,2-diphenyl1-picryhydrazyl free radical (DPPH) scavenging assay (BrandWilliams et al., 1995). The antioxidant activity was expressed as the $\mathrm{IC}_{50}$ ratio (Inhibition Concentration, $\mathrm{ppm}$ ) which indicates the sample's concentration required to reduce the initial concentration of blank DPPH by $50 \%$, thus lower $\mathrm{IC}_{50}$ values indicate higher antioxidant activity.

Initially, different concentrations of the test sample were prepared in test tubes. In each of these test tubes, $3 \mathrm{~mL}$ of DPPH stock solution $\left(10^{4} \mathrm{M}\right)$ diluted in aqueous methanol $(70: 30 \mathrm{v} / \mathrm{v})$, was added. The mixtures were stirred vigorously and allowed to stand at room temperature and in the dark for $30 \mathrm{~min}$. The reduction in absorbance at $517 \mathrm{~nm}$, was measured against aqueous methanol solution (blank). A mixture of $1 \mathrm{~mL}$ aqueous methanol $(70: 30 \mathrm{v} / \mathrm{v})$ and $3 \mathrm{~mL}$ of DPPH solution was used as a control. The percentage inhibition of DPPH for each sample was calculated according to the following formula:

$$
\% \text { Inhibition }=\frac{\mathrm{A}_{\mathrm{B}}-\mathrm{A}_{\mathrm{A}}}{\mathrm{A}_{\mathrm{A}}} \times 100
$$

where $A_{B}$ was the absorbance of the control and $A_{A}$ the absorbance of the test sample.

\section{Statistical analysis}

The experimental design was a Completely Randomized Design. Normality of the data was tested using the Shapiro-Wilk normality test and comparisons among the means were performed using the Least Significant Difference (LSD). Correlation between the antioxidant activity and the total phenolic content was tested for each tissue separately using the Pearson Correlation Coefficient. All statistical analyses were performed using the JMPIN 8 software.

\section{Results}

The total phenolic content and the antioxidant activity of the different tissues for all studied varieties were determined and their values are presented in Figs. 1 to 4. Figs. 1 and 2 show the values of the measured parameters for the second year, whereas Figs. 3 and 4 for the first year. Regarding the second year's results, the total phenolic content and total antioxidant activity of all 
varieties per tissue varied significantly since different varieties exhibited statistically significant different values. For the new season leaves collected in April, 'Kalamata' presented the statistically significant higher phenolic content $(18.7 \mathrm{mg} \mathrm{GAE} / \mathrm{g}$ f.t.) followed by 'Konservolia', 'Chalkidiki', 'Lianolia Kerkyras', 'Mastoidis', 'Gaidourelia', 'Arbequina', 'Koroneiki', 'Megaritiki' and 'Adramytini' which showed the statistically significant lower phenolic content ( $12.5 \mathrm{mg}$ GAE/g f.t.). Regarding the antioxidant activity there were no statistical differences between varieties, with the exception of variety 'Adramytini' which showed the statistically significant lower antioxidant activity. From the leaves collected in September, variety 'Arbequina' showed the statistically significant higher concentration of total phenols (15.3 mg GAE/g f.t.) compared to the other varieties, followed by 'Kalamata', 'Adramytini', 'Konservolia', 'Koroneiki', 'Gaidourelia', 'Megaritiki', 'Lianolia Kerkyras', 'Chalkidiki' and 'Mastoidis' which showed the statistically significant lower phenolic content (10.6 mg GAE/g f.t.). Antioxidant activity did not exhibit any statistically significant difference among all varieties. From the leaves collected in December, variety 'Arbequina' (similarly as in leaves collected in September in year 2) and 'Chalkidiki' presented the statistically significant higher concentration in total phenols among all varieties $(17 \mathrm{mg} \mathrm{GAE} / \mathrm{g}$ f.t.). 'Arbequina' as well as 'Chalkidiki' and 'Mastoidis' presented statistically significant higher antioxidant activity compared to the remaining varieties. In that year, due to biennial bearing, the collection of green drupes was possible only for five varieties and that of black drupes only for four varieties. Green drupes of variety 'Lianolia Kerkyras' exhibited the statistically significant higher values for both the phenolic content (13.9 mg GAE/g f.t.) and the antioxidant activity. Variety 'Konservolia' had statistically significant lower phenolic content $(4.1 \mathrm{mg} \mathrm{GAE} / \mathrm{g}$ f.t.) as well as antioxidant activity. Among black drupes, variety 'Mastoidis' had statistically significant higher phenolic content (10.1 mg GAE/g f.t.). 'Mastoidis' and 'Lianolia Kerkyras' had statistically significant highest antioxidant activity among all varieties. 'Koroneiki' and 'Konservolia' presented the statistically significant lower phenolic content (5.6 mg GAE/g f.t.). and antioxidant activity. Within the same variety, tissue was an important parameter for both the total phenolic content and the antioxidant activity, as different tissues exhibited statistically significant differences for both parameters (Figs. 1 and 2). The phenolic content varied among the tissues and ranged between
12.5-18.7 mg GAE/g f.t. for new season leaves collected in April, 10.6-15.3 mg GAE/g f.t. for leaves collected in September, 10.3$17 \mathrm{mg} \mathrm{GAE} / \mathrm{g}$ f.t. for leaves collected in December, $4.1-13.9 \mathrm{mg}$ $\mathrm{GAE} / \mathrm{g}$ f.t. for green drupes and 5.6-10.1 mg GAE/g f.t. for black drupes.

New season leaves collected in April from varieties 'Kalamata', 'Konservolia', 'Chalkidiki' and 'Mastoidis', showed statistically significant higher phenolic content than the leaves collected in September and December, as well as green and black drupes of the same year (Fig. 1). Regarding the antioxidant activity (Fig. 2) new season leaves collected in April from varieties 'Kalamata', 'Konservolia', 'Lianolia Kerkyras' and 'Gaidourelia' showed statistically significant higher antioxidant activity from the leaves collected on September and December.

In the first year of the experiment, new season leaves were collected in April and green and black drupes were collected in October and December, respectively. The results where similar with those of the second year and as presented in Fig. 3, there were statistical differences in the total phenolic content between varieties. For new season leaves, variety 'Konservolia' showed the statistically significant higher phenolic content $(20.6 \mathrm{mg} \mathrm{GAE} / \mathrm{g}$ f.t.) compared to the rest, whereas variety 'Adramytini' presented the statistically significant lower phenolic content $(10.1 \mathrm{mg}$ $\mathrm{GAE} / \mathrm{g}$ f.t.). Regarding the antioxidant activity there were no statistical differences among all varieties. For green drupes variety 'Mastoidis' exhibited the statistically significant higher phenolic content (19.8 mg GAE/g f.t.) whereas varieties 'Adramytini' and 'Megaritiki' presented the statistically significant lower phenolic content (5.9 mg GAE/g f.t.). Variety 'Megaritiki' also presented the statistically significant lower antioxidant activity. Black drupes were collected from only five varieties due to an extensive entomological infestation. Out of the five varieties, variety 'Lianolia Kerkyras' exhibited the statistically significant higher phenolic content $(9.9 \mathrm{mg}$ GAE/g f.t.) whereas variety 'Gaidourelia' the statistically significant lowest ( $5.4 \mathrm{mg} \mathrm{GAE} / \mathrm{g}$ f.t.). 'Lianolia Kerkyras' also presented the statistically significant highest antioxidant activity, whereas variety 'Chalkidiki' the lowest.

During the same year, within the same variety, tissue was an important parameter for both the total phenolic content and the antioxidant activity, and in agreement to our observations for the second year. Different tissues exhibited statistically significant different values for both parameters (Figs. 3 and 4). The phenolic

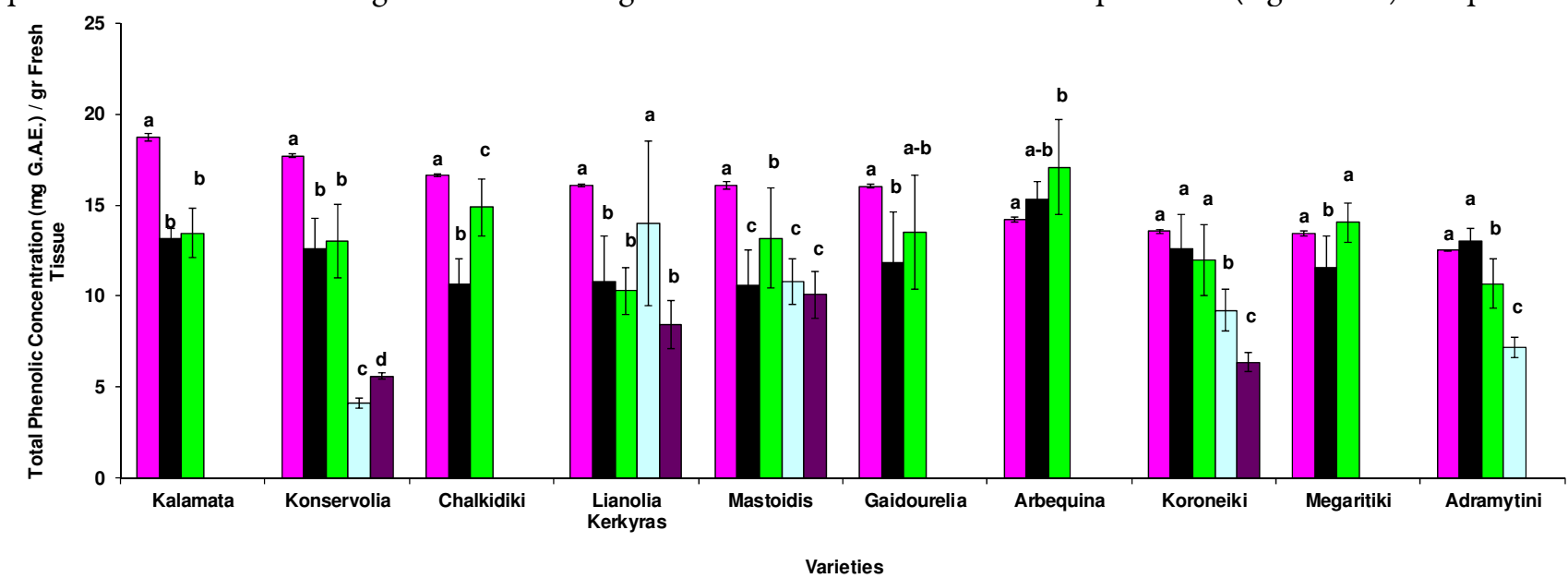

Fig. 1. Total phenolic content of new season leaves of April $(\square)$, September leaves $(\square)$, December leaves $(\square)$, green drupes $(\square)$ and black drupes $(\square)$ for all studied varieties in year 2. Different letters indicate statistically significant differences between tissues within each variety (p $<0.05$ ) 


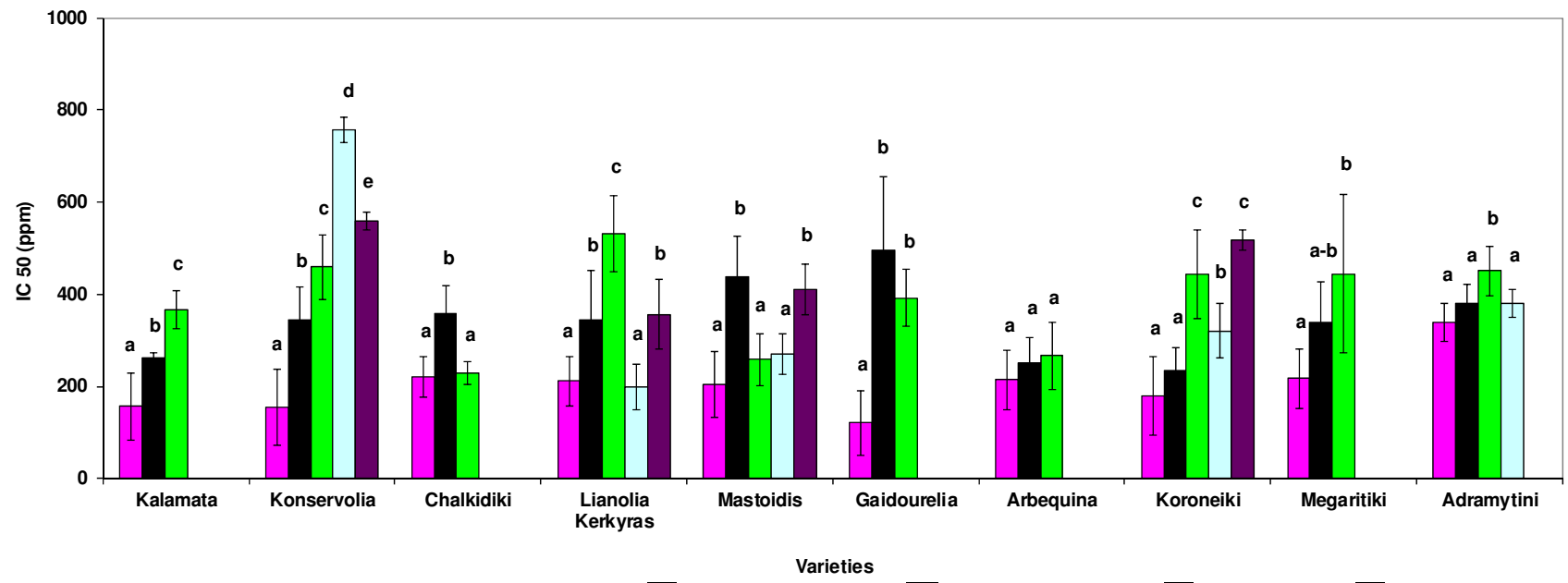

Fig. 2. Antioxidant activity $\left(\mathrm{IC}_{50}\right)$ of new season leaves of April (

) for all studied varieties in year 2. Different letters indicate statistically significant differences between tissues within each variety $(\mathrm{p}<0.05)$

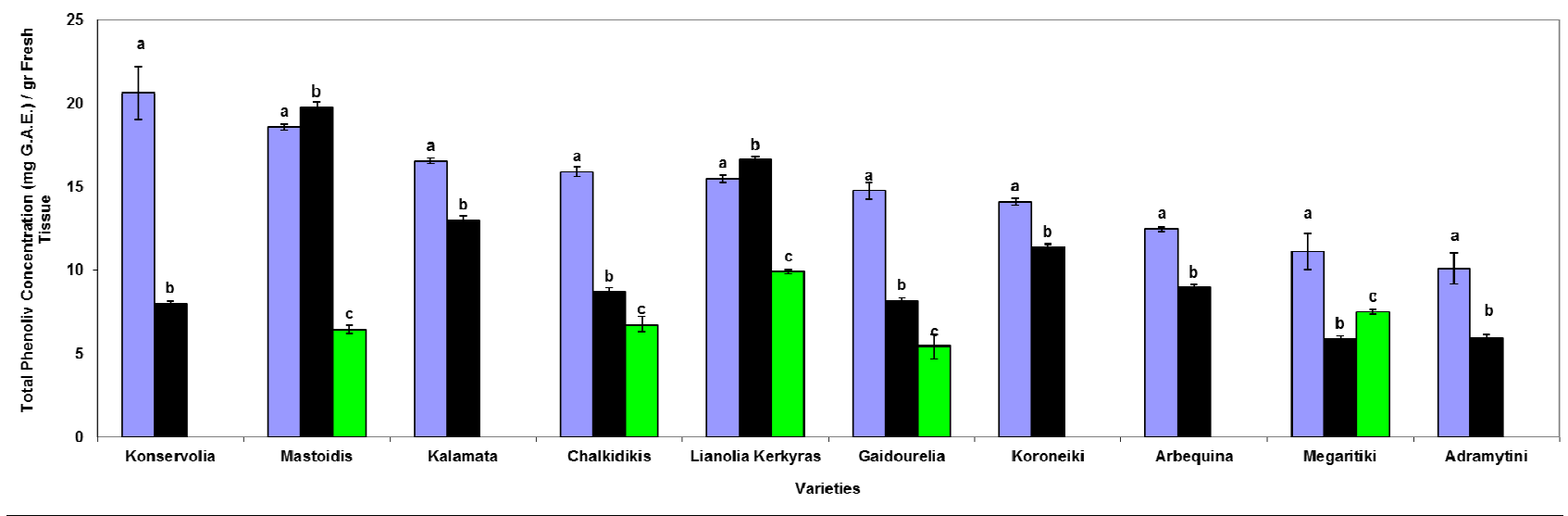

Fig. 3. Total phenolic content for new season leaves of April $(\square)$, green drupes $(\square)$ and black drupes $(\square)$ for the studied varieties in year 1. Different letters indicate statistically significant differences between tissues within each variety $(\mathrm{p}<0.05)$

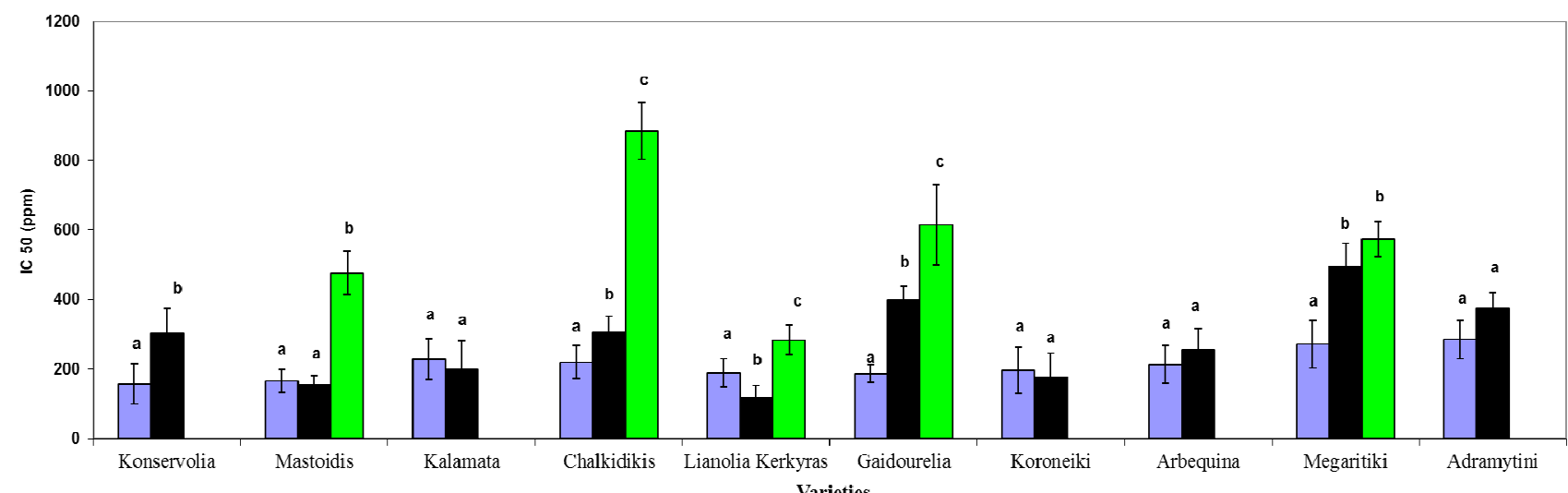

Fig. 4. Antioxidant activity $\left(\mathrm{IC}_{50}\right)$ for new season leaves of April $(\square)$, green drupes $(\square)$ and black drupes $(\square)$ for the studied varieties in year 1. Different letters indicate statistically significant differences between tissues within each variety $(\mathrm{p}<0.05)$

content within the same variety varied among the tissues and it was in the range of 10.1-20.6 mg GAE/g f.t. for new season leaves collected in April, followed by green drupes with a content of 5.9-19.8 mg GAE/g f.t. and black drupes with 5.4-9.9 mg GAE/g f.t.. New season leaves for all varieties, showed statistically significant higher phenolic content than green and black drupes with the exception of varieties 'Mastoidis' and 'Lianolia Kerkyras' where green drupes presented statistically significant higher phenolic content than the new season leaves (Fig. 3). Regarding the antioxidant activity, new season leaves of varieties
'Megaritiki', 'Gaidourelia', 'Chalkidiki' and 'Konservolia' presented statistically significant higher antioxidant activity compared to that of green and black drupes (Fig. 4). All black drupes presented statistically significant lower antioxidant activity compared to that of new season leaves and green drupes, with the exception of variety 'Megaritiki' (Fig. 4).

Comparing the two years, most varieties presented statistically significant higher total phenolic content in new season leaves collected in the second year than those of the first year with the exception of varieties 'Konservolia', 'Mastoidis' and 
'Koroneiki'. There were no statistical differences in antioxidant activity among new leaves of April for both years for all varieties. New season leaves of April of the variety 'Adramytini' showed statistically significant lower total phenolic content for both years. On the contrary, varieties 'Konservolia' and 'Kalamata' were the varieties which presented statistically significant higher total phenolic content for both years.

Green drupes collected the first year for all varieties showed statistically significant higher total phenolic content compared to green drupes collected during the second year, with the exception of variety 'Adramytini' where green drupes collected the second year showed statistically significant higher total phenolic content in relation to green drupes collected in the first year of the experiment. Regarding antioxidant activity, first year green drupes, had significantly higher values than that of green drupes of the second year with the exception, once again, of variety 'Adramytini'. This variety showed no statistical difference between the two years in antioxidant activity. Varieties 'Lianolia Kerkyras' and 'Mastoidis' were among the varieties which presented statistically significant higher total phenolic content for both years.

The correlation between phenolic content and antioxidant activity within the ten varieties was significant positive $(r=0.793)$. Fig. 5 shows the regression line for a representative selected tissue between the total phenolic content and the $\mathrm{IC}_{50}$ values (low $\mathrm{IC}_{50}$ values correspond to higher antioxidant activity). The coefficient of determination revealed that the proportion of variance in total phenolic concentration of fresh tissue, predictable from the antioxidant activity was almost $63 \%\left(\mathrm{R}^{2}=0.6295\right)$.

\section{Discussion}

In the present study the concentration of total phenols and the antioxidant activity were studied in ten olive varieties extracted from different tissues (leaves, green and black drupes) for two consecutive years. For the varieties studied, and for both years, new season leaves of April showed the highest concentration of total phenols followed by green and black drupes, with a few exceptions. The observed differences in total phenolic content between different tissues can be attributed to the diversity of phenolic compounds and their different distribution in

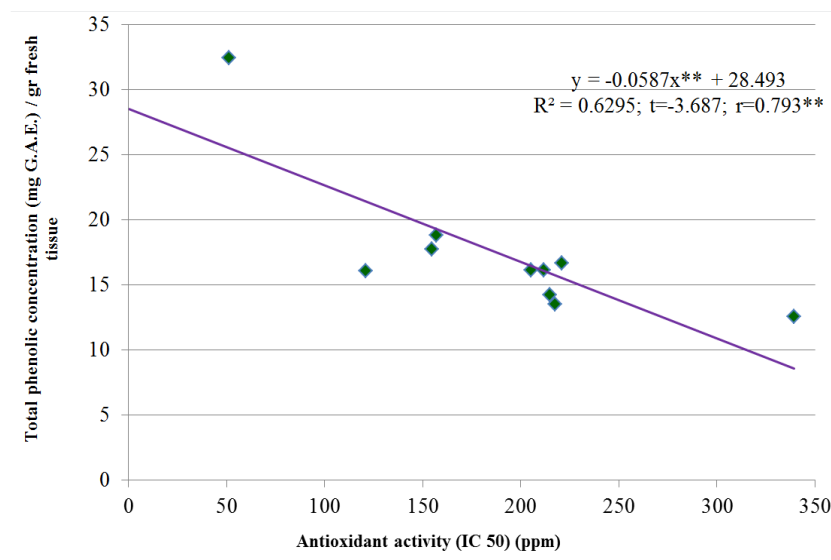

Fig. 5. Regression of antioxidant activity and total phenolic content in new season leaves for the second year; coefficient of determination $\left(\mathrm{R}^{2}\right)$ and coefficient of correlation $(\mathrm{r})$ plant tissues. Silva et al. (2006) studied drupes and leaves of ten Portuguese varieties. According to their results, the total phenols in the optimum ripening stage (January) for fresh leaves ranged between 11.6-17.4 g/Kg. Despite the different varieties studied, these results are in good agreement, with the results of the present study since the total phenolic content for December leaves ranged also from 10.3 to 17 $\mathrm{mg}$ GAE/g f.t. They also reported that the increase in phenolic content after the drying process could be due to the formation of compounds that react with the FolinDenis reagent or to the conversion of oleuropein glucoside to oleuropein.

In the present work, a decrease in the total phenolic content during leaf maturation and drupe ripening was observed. For most varieties, new season leaves of April showed higher total phenolic concentration than the leaves of September and December. Regarding drupes, for both years, the green ones had a greater phenolic content than black ones with the exception of 'Megaritiki' and 'Konservolia' for the first and the second years, respectively. Morello et al. (2004) studied the effect of the ripening process on the phenolic content of drupes for the varieties 'Arbequina', 'Farga' and 'Morrut'. They reported that the concentration of total phenolics decreased during ripening an observation that is also supported by the data of the present study.

The effect of maturation on the phenolic content of drupes in two Italian varieties ('Ascolana Tenera' and 'Frantoio Seedling no.17') was studied by Briante et al. (2002). They also concluded that the total phenolic concentration decreased during ripening. FernandezOrozco et al. (2011), who studied the change in the total phenolic concentration of the drupes of the variety 'Arbequina' during their maturation, in conventional and organic cultures reached in the same conclusion. For both organic and conventional cultivations they observed an increase in the total phenolic concentration during the first three weeks of ripening period and then a gradual decrease over time. Similar observations, regarding the reduction of phenolic content during maturation, have also been reported by Amiot et al. (1986 and 1989), and Ryan et al. (1999). On the contrary, Bouaziz et al. (2010) observed an increase of the concentration of total phenolics during the ripening of drupes.

One of the main aims of this study was to compare the major Greek olive varieties in regard to their phenolic content, since international literature has limited reports on the matter. Thus, comparing the different varieties, variety 'Konservolia' showed the highest concentration of total phenols in new season leaves of April for one year and variety 'Kalamata' in new season leaves of the other year. Variety 'Arbequina' showed the highest concentration of total phenols in September and December leaves of the second year. Regarding green drupes variety 'Mastoidis' showed the highest concentration of total phenols for the first year and variety 'Lianolia Kerkyras' for the second year. 'Lianolia Kerkyras' also presented the highest concentration of total phenols in black drupes for the first year and 'Mastoidis' for black drupes of the second year. Kiritsakis et al. (2010) reported that total phenolic content in fall leaves of the variety 'Kalamata' was lower than the varieties 'Megaritiki' and 'Koroneiki'. The present study showed no 
160

statistical differences between those three varieties in leaves collected on September. Blekas et al. (2002) studied the differences in concentration of total phenols in processed drupes for varieties 'Nychati Kalamata', 'Konservolia' and 'Chalkidiki'. The 'Nychati Kalamata' showed the highest concentration of total phenols followed by the varieties 'Chalkidiki' and 'Konservolia'. These results are not comparable with the results of this study, as drupe processing methods bring changes both in the quality and quantity of phenolic compounds and therefore in the total phenolic content.

Olive trees present the phenomenon of alternate bearing. It has been found that the concentration of phenolic compounds, amino acids and proteins are usually increased during the spring and summer of the year presenting higher yield. During the first year an increased production in comparison with the second year was observed. In new season leaves of April of the first year the total phenolic content ranged between 10.1-20.6 mg GAE/g f.t. whereas in new season leaves of April of the second year the total phenolic content ranged between 12.5$18.7 \mathrm{mg} \mathrm{GAE} / \mathrm{g}$ f.t. Additionally, green drupes collected in year 1 presented higher phenolic content than green drupes collected in year 2 .

The results of this study also showed that different varieties showed different antioxidant activity in all tissues for both years. Kiritsakis et al. (2010) found no statistically significant differences between the three varieties, i.e. 'Kalamata', 'Megaritiki' and 'Koroneiki', which were studied in terms of their antioxidant activity. This observation could be due to the great diversity and complexity of mixtures of phenolic compounds in different varieties as well as to small differences between varieties in terms of the total phenolic content.

Furthermore, the present study reported that for all tissues and for both years there was a positive correlation between concentration of total phenols and antioxidant activity. Highest concentration of total phenolics was accompanied by highest antioxidant activity. Similar results have been presented by Bouaziz et al. (2010), Pereira et al. (2006) and Fernandez-Orozco et al. (2011) who also reported a positive correlation between the two parameters among different varieties.

\section{Conclusions}

The present work presented the total phenolic content and the antioxidant activity of leaves and drupes of ten olive varieties collected at different seasons during two consecutive years. The data obtained from this work showed that the total phenolic content and the antioxidant activity of all varieties per tissue have varied significantly since different varieties exhibited statistically significant different values. Also within the same variety, tissue was an important parameter for both the total phenolic content and the antioxidant activity, as different tissues exhibited statistically significant different values for both parameters. For the varieties studied, and for both years, new season leaves on April showed the highest total phenolic content followed by green and black drupes with a few exceptions. Also new season leaves on April showed the highest total phenolic content than the leaves of September and
December of the same year with a few exceptions also. Finally for all tissues and for both years, there was a positive correlation between total phenolic content and antioxidant activity.

\section{Acknowledgment}

The authors would like to thank Assistant Professor Vassiliki Evageliou (Dept of Food Science and Human Nutrition, Agricultural University of Athens) for helpful discussion and technical assistance.

\section{References}

Amiot MJ, Fleuriet A, Macheix JJ (1989). Accumulation of oleuropein derivatives during olive maturation. Phytochemistry 28:67-70.

Amiot MJ, Fleuriet A, Macheix JJ (1986). Importance and evolution of phenolic compounds in olive during growth and maturation. Journal of Agriculture and Food Chemistry 34:823-826.

Andrikopoulos NK, Kaliora AC, Assimopoulou AN, Papageorgiou VP (2002). Inhibitory activity of minor polyphenolic and non-polyphenolic constituents of olive oil against the in vitro LDL oxidation. Journal of Medicinal Food 5(1):1-7.

Blekas G, Vassilakis C, Harizanis C, Tsimidou M, Boskou DG (2002). Biophenols in table olives. Journal of Agriculture and Food Chemistry 50:3688-3692.

Bouaziz M, Jemai H, Khabou W, Sayadi S (2010). Oil content, phenolic profiling and antioxidant potential of Tunisian olive drupes. Journal of the Science of Food and Agriculture 90:1750-1758.

Brand-Williams W, Cuvelier ME, Berset C (1995). Use of a free radical method to evaluate antioxidant activity. LWT-Food Science and Technology 28:25-30.

Briante R, Patumi M, Limongelli S, Febbraio F, Vaccaro C, Di Salle A, La Cara F, Nucci R (2002). Changes in phenolic and enzymatic activities content during fruit ripening in two Italian cultivars of Olea europaea $\mathrm{L}$. PlantScience 162:791-798.

Fernandez-Orozco R, Roca M, Gandul-Rojas B, Gallardo-Guerrero L (2011). DPPH-scavenging capacity of chloroplastic pigments and phenolic compounds of olive fruits (cv Arbequina) during ripening. Journal of Food Composition and Analysis 24:858-864.

Ghisalberti EL (1998). Biological and pharmacological activity of naturally occurring iridoids and secoiridoids. Phytomedicine 5(2):147-163.

Gonzalez M, Zarzuelo A, Gamez MJ, Utrilla MP, Jimenez J, Osuna I (1992). Hypoglycemic activity of oliveleaf. Planta Medica 58:513-515.

Harborne JB (1993). Advances in chemical ecology. Natural Product Reports 10:327-348.

Hertog MGL, Kromhout D, Aravanis C, Blackburn H, Buzina R, Fidanza F, Giampaoli S, Jansen A, Menotti A, Nedelikovic S (1995). Flavonoid intake and long-term risk of coronary heart disease and cancer in the seven countries study. Archives of Internal Medicine 155:381-386.

Kiritsakis K, Kontominas MG, Kontogiorgis C, Hadjipavlou-Litina D, Moustakas A Kiritsakis A (2010). Composition and antioxidant activity of olive leaf extracts from Greek olive cultivars. Journal of the American OilChemists Society 87:369-376.

Kris-Etherton PM, Hecker KD, Bonanome A, Coval SM, Binkoski AE, 
Hilpert KF (2002). Bioactive compounds in foods: Their role in the prevention of cardiovascular disease and cancer. The American Journal of Medicine 113(9B):71-78.

Le Tutour B, Guedon D (1992). Antioxidative activities of Olea europaea leaves and related phenolic compounds. Phytochemistry 31(4):11731178.

Markham KR, Gould KS, Winefield CS, Mitchell KA, Bloor SJ, Boase MR (2000) Anthocyanic vacuolar inclusions - their nature and significance in flower colouration. Phytochemistry 55:327-336.

Morello JR, Romero MP, Motilva MJ (2004). Effect of the maturation process of the olive fruit on the phenolic fraction of drupes and oils from Arbequina, Farga, and Morrut cultivars. Journal of Agriculture and Food Chemistry 52:6002-6009.

Owen RW, Giacosa A, Hull WE, Haubner R, Spiegelhalder B, Bartsch H (2000). The antioxidant/anticancer potential of phenolic compounds isolated from olive oil. European Journal of Cancer 36:1235-1247.

Pereira JÁ, Pereira APG, Ferreira ICFR, Valentão P, Andrade PB, Seabra R, Estevinho L, Bento A (2006). Table olives from Portugal: phenolic compounds, antioxidant potential, and antimicrobial activity. Journal of Agriculture and Food Chemistry 54:8425-8431.

Ryan D, Antolovich M, Herlt T, Prenzler PD, Lavee S, Robards K (2002). Identification of phenolic compounds in tissues of the novel olive cultivar Hardy's Mammoth. Journal of Agriculture and Food Chemistry 50:6716-6724.

Ryan D, Robards K (1998). Phenolic compounds in olives. Analyst 123:3144.

Ryan D, Robards K, Lavee S (1999). Changes in the phenolic content of olive during maturation. International Journal of Food Science and Technology 34:265-274.
Silva S, Gomes L, Leitao F, Coelho AV, Vilas Boas L (2006). Phenolic compounds and antioxidant activity of Olea europaea $\mathrm{L}$. fruits and leaves. International Journal of Food Science and Technology 12(5):385-396.

Singleton VL, Rossi JA (1965). Colorimetry of total phenolics with phosphomolybdic-phosphotungstic acid reagentes. American Journal of Enology and Viticulture 16:144-158.

Singleton VL, Orthofer R, Lamuela-Raventos RM (1999). Analysis of total phenols and other oxidation substrates and antioxidants by means of Folin-Ciocalteu reagent. Methods Enzymology 299:152-178.

Soler-Rivas C, Espin JC, Wichers HJ (2000). Oleuropein and related compounds. Journal of the Science of Food and Agriculture 80:10131023.

Vermerris W, Nicholson R (2006). Phenolic compounds and their effect on human health. In: Vermerris W, Nicholson R (Eds). Phenolic Compound Biochemistry. Springer, Dordrecht, The Netherlands pp 246-250.

Visioli F, Galli C (1994). Oleuropein protects low density lipoprotein from oxidation. LifeScience Journal 55(24):1965-1971.

Visioli F, Galli C (1998). The effect of minor constituents of olive oil on cardiovascular disease: New findings. Nutrition Reviews 56(5):142-147.

Walter Jr WM, Fleming HP, Etchells JL (1973). Preparation of antimicrobial compounds by hydrolysis of oleuropein from green olives. Applied Microbiology 26(5):773-776.

Whetten R, SederoffR(1995). Lignin biosynthesis. Plant Cell 7:1001-1013.

Zarzuelo A, Duarte J, Jimenez J, Gonzales M, Utrilla P (1991). Vasodilator effect of oliveleaf.Planta Medica 57:417-419.

Ziyyat A, Leggsyer A, Mekhfi H, Dassouli A, Serhrouchni M, Benjelloun W (1997). Phytotherapy of hypertention and diabetes in oriental Morocco. Journal of Ethnopharmacology 58:45-54. 